\title{
Junior hospital doctors' views on their training in the UK
}

\author{
Barnabus N Panayiotou, Martin D Fotherby
}

\begin{abstract}
Summary
To ascertain the views of senior house officers and registrars on the educational and training component of their posts, a questionnaire was sent to all full-time doctors working in training posts in general and/or geriatric medicine at three district general and three teaching hospitals. Completed questionnaires were received from 64 (61\%) of 105 doctors who were contacted. Most had a careers counsellor or tutor, although less than twothirds thought they had benefited from this arrangement. The majority of doctors attended at least two medical tutorials or meetings per week; most wanted to attend more but were unable to because of other work commitments. Supervision by more senior staff on the ward was deemed by most to be satisfactory, but less so in outpatient clinics. Overall, one-third of doctors thought that training was inadequate and three-quarters wanted a greater amount of formal education. The majority of junior doctors' time was spent on routine work and most considered 'training' constituted less than $10 \%$ of their working time. Doctors in training require more sessions designated as educational, with protected time to attend these.
\end{abstract}

Keywords: training

A number of initiatives to improve junior doctors' education, training and working conditions have recently been introduced. Working for patients ${ }^{1}$ established protected funding and an education contract between postgraduate deans and local clinical tutors; the Department of Health Directive EC (92)63 placed $50 \%$ of the trainees' salaries in the Postgraduate Dean's budget to emphasise the educational component of junior posts ${ }^{2}$; and the General Medical Council's Revised Recommendations on General Clinical Training ${ }^{3}$ called for protected time for formal education, reduction of inappropriate duties and ensuring adequate educational and clinical supervision. The 'new deal' which requires hospitals to limit doctors' hours ${ }^{4}$ has also been implemented. Junior doctors in general medicine and geriatrics work in a hard pressed speciality. In particular, they undertake much of the emergency care of patients out of 'normal working hours' when staffing levels and supporting services are reduced. The training of junior doctors in any specialty requires considerably more than just job 'experience', and their high level of service commitment to routine medical duties needs to be carefully balanced against time devoted to their educational and training needs. To ensure satisfactory progress in the improvement of training posts, it is essential that the effects of new initiatives are closely monitored. We therefore recently carried out a survey to elicit the views of junior doctors regarding their current training posts.

\section{Methods}

The survey was performed in six hospitals in the Midlands, three university and three district general hospitals. All hospitals had library facilities and centres for postgraduate activities. Full-time senior house officers and registrars in Departments of General Medicine, Geriatric Medicine or Integrated Medicine were identified from current medical staffing lists. Doctors working in subspecialties without duties in general medicine, eg, dermatology and genito-urinary medicine were not included in the study. A questionnaire (reproduced in the Appendix) comprising 10 questions, to be completed anonymously, was sent to each doctor with an addressed envelope for return.

\section{Results}

A total of 105 senior house officers and registrars were sent the questionnaire which was returned by $64(61 \%)$, comprising 46 $(72 \%)$ senior house officers and $18(28 \%)$ registrars. Response rates were similar from district general $(28 / 42,67 \%)$ and teaching hospitals $(38 / 63,60 \%)$. As the pattern of responses from district general and teaching hospitals to most questions were similar, the results from both were considered together; where differences were seen, these are stated.

\section{CLINICAL TUTORS}

All except five doctors (8\%) responding reported having a tutor they could discuss training and career plans with; of those that did not, four worked in a district general and one in a teaching hospital. All five doctors who did not have a clinical tutor stated a desire for one.

For nearly all doctors their tutor was either a past or their present consultant; in only four cases $(6 \%)$ was this person a designated clinical or postgraduate tutor. Half of the respondents thought that the choice of a tutor should be left

\section{UK \\ Department of Clinical North Staffordshire Department of Elderly, The Glenfield Hospital, Groby Road,}

Correspondence to Dr MD Accepted 17 January 1996

M


Table 1 Attendance of senior house officers and registrars at medical meetings

\begin{tabular}{lll}
\hline Meetings/week & Actually attended & Would like to attend \\
\hline$<1$ & $10(15 \%)$ & $1(2 \%)$ \\
1 & $22(34 \%)$ & $6(13 \%)$ \\
2 & $32(50 \%)$ & $15(32 \%)$ \\
3 & $1(1 \%)$ & $22(47 \%)$ \\
\hline
\end{tabular}

${ }^{\star}$ Four $(6 \%)$ wanted to attend as many meetings as possible

up to them and half felt such a person should be designated on their behalf. Most (61\%) doctors felt that they had benefited from having a tutor, but $19 \%$ thought they definitely had not, while $20 \%$ were unsure.

\section{ATTENDANCE AT MEDICAL MEETINGS}

The frequency of attendance at hospital medical meetings and the number of meetings doctors would like to attend per week are shown in table 1. The majority of doctors attended one or two meetings per week, but many wished to attend more. An average of 1.4 meetings were attended by each doctor per week with no differences between hospital type. When asked directly, $60 \%$ stated they would like to attend more meetings but felt unable to, the main reason given by $89 \%$ being heavy clinical commitments.

\section{SUPERVISION}

As shown in table 2 the majority of senior house officers and registrars felt that they received adequate supervision on the wards, but many were critical of the level of outpatient supervision. Of the senior house officers, $14(30 \%)$ considered out-patient supervision to be unsatisfactory.

\section{TRAINING}

Table 2 also shows that one-third of doctors considered the training content of their present job to be unsatisfactory and almost three-

Table 2 Satisfaction of senior house officers and registrars with supervision and training

\begin{tabular}{|c|c|c|c|c|}
\hline & \multicolumn{2}{|c|}{$\begin{array}{l}\text { Receiving adequate supervision } \\
(\%)\end{array}$} & \multirow{2}{*}{$\begin{array}{l}\text { Receiving } \\
\text { adequate } \\
\text { training (\%) }\end{array}$} & \multirow{2}{*}{$\begin{array}{l}\text { Desiring } \\
\text { more } \\
\text { training (\%) }\end{array}$} \\
\hline & on ward & in out-patients & & \\
\hline Yes & $54(85)$ & $46(72)$ & $39(61)$ & $47(74)$ \\
\hline No & $6(10)$ & $15(23)$ & $22(34)$ & $5(9)$ \\
\hline Sometimes & $3(4)$ & $2(3)$ & - & - \\
\hline Don't know & $1(1)$ & $1(2)$ & $3(5)$ & $12(18)$ \\
\hline
\end{tabular}

Table 3 Allocation of working time of senior house officers and Registrars

\begin{tabular}{llll}
\hline \multirow{4}{*}{$\%$ time } & \multicolumn{3}{l}{ Proportion of working time spent on } \\
\cline { 2 - 3 } & \multicolumn{1}{l}{ Routine service work (\%) Interesting work (\%) } & 'Training' (\%) \\
\hline$>75$ & $22(34)$ & $3(5)$ & $0(0)$ \\
$50-74$ & $21(33)$ & $6(10)$ & $3(5)$ \\
$25-49$ & $6(10)$ & $13(20)$ & $6(9)$ \\
$<25$ & $9(14)$ & $35(54)$ & $50(78)$ \\
Don't know & $6(10)$ & $7(11)$ & $5(9)$ \\
\hline
\end{tabular}

quarters wanted the training element to form a greater part of their working time.

An attempt was made to find out how much of their working time doctors spent (a) doing routine work lacking any training element, ( doing work considered more interesting, (ब्ष doing work with a specific training aspect of clinical nature, and (d) attending formal mee ings; the results are summarised in table Most respondents considered the majority of their time to be spent on routine work and les] than one-quarter on what they consider inter esting work, while 'clinical training' occupieg only $10 \%$ of work time; in fact $9 \%$ of doctor considered that none of their time involved training. Of three doctors who considered mors than $50 \%$ of their time was spent in training two were from a district general hospital.

Regarding training in terms of formal talks and meetings, $80 \%$ of all doctors considere they spent up to $11 \%$ of their time involve with these and only $9 \%$ of doctors thought the spent a greater proportion of their time in such activities ( $11 \%$ were unsure). The responsest from doctors working in district general and teaching hospitals were similar.

The further areas and modes of training sought by senior house officers and registrars is summarised in table 4. MRCP Part I and go orientated teaching and discussion on aspects of patient management were the most populan areas for further training sessions. The three respondents wanting research-orientated training were from district general hospitals.

\section{STUDY LEAVE}

Thirteen (20\%) respondents reported pros blems obtaining study leave, seven of whon worked in district general hospitals and six i teaching hospitals. Only seven of these pro을 vided reasons for the difficulty obtaining stud $\overrightarrow{\bar{\phi}}$ leave; three reported they could not get colleagues to cover their absence and in foug cases no funds were made available.

\section{Discussion}

Senior house officers were the predominang group in the survey, reflecting their prevalence् in National Health Service Hospitals. Althougld senior house officers and registrars may have some difference in their educational needs, we addressed important issues which are common to both grades. We found no major difference in the responses to the questionnaire betweer doctors in the two grades, or between district general and teaching hospitals. This woulळ suggest that existing problems with training are encountered widely, and is consistent with previous finding that trainees' participation in postgraduate educational activities was no 5 influenced by the type of hospital. ${ }^{5}$ Education and training of junior doctors has been discussed repeatedly over many years, ${ }^{6-9}$ buf progress has been unsatisfactory and junior doctors have been reported to be exhausted? stressed and demoralised. ${ }^{10-14}$ It was therefore disappointing to find that, despite the mos recent initiatives, ${ }^{1-4}$ considerable deficiencies persist in doctors' training posts. 


\section{Summary/learning points}

- $8 \%$ senior house officers and registrars did not have a clinical tutor and only $61 \%$ felt they obtained some benefit from a tutor

Under Calman proposals an educational supervisor will be required by every trainee to undertake a formal appraisal of performance and identify short-falls in training. Greater effort and time will need to be put into selecting, training and supporting such supervisors if they are to adopt their enhanced role successfully

- trainees attended on average 1.4 medical meetings per week, most (60\%) wanted to attend more but felt unable to because of clinical commitments

- the majority of doctors (55\%) claimed they spent less than $10 \%$ of their working time in activities with a 'training' element

- a third of respondents considered they received inadequate training and three-quarters desired more Senior house officers and registrars require protected time from routine clinical duties to attend teaching sessions of relevance. The challenge is to incorporate into routine service work a greater training element through regular review and supervision of work by seniors and a reduction in time spent on nonmedical chores

- most junior doctors wanted teaching orientated to exams for MRCP and directly to patient management

- supervision of out-patient work was often unsatisfactory

- $20 \%$ of junior doctors surveyed had difficulties obtaining study leave

Requesting legitimate study leave should be actively encouraged

Every doctor should have a tutor to whom they can turn to for advice, but many did not, while $19 \%$ of our sample reported they did not benefit from this. How tutors are selected, their skills and the reasons for not meeting trainees' requirements should be addressed by each individual hospital. Inherent in the Calman proposals $^{15}$ for the new specialist registrar grade, is the formal appointment of an educational supervisor for each trainee, with formal appraisal exercises at regular intervals, opportunity for feedback from trainees and identification of shortfalls in training. Emphasis will also be placed on a much more structured training programme with a clearly defined curriculum and objectives, and organised teaching sessions, together with protected time to attend them. This contrasts with the current situation whereby education has all too often been a secondary and somehow inevitable 'osmotic' process. Although the implementation of the Calman proposals is concerned with the registrar grade, senior house officers have similar requirements ${ }^{16}$ and the ultimate objective is to integrate these two grades into a single, unified training grade. ${ }^{15,16}$ The General Medical Council recommends that preregistration house officers should also have educational supervisors, to help with professional and personal development. ${ }^{3}$ With calls for more structured training and better supervision for all grades, ${ }^{17}$ and the movement of trainees' salaries to the Postgraduate Deans, it will be the task of Postgraduate Deans to ensure that improved training programmes are implemented and monitored.

Although the process of training entails the acquisition of knowledge, experience, skills and competence in the diagnosis and treatment of patients, there are many duties currently performed by junior doctors which are of no or little educational value. These include tasks such as finding beds for admissions, routine phlebotomy, arranging investigations, filling forms and chasing results. While these tasks need to be carried out, it is inappropriate for trainees to spend a considerable portion of their time performing them. ${ }^{12}$ It was disturbing to find that most doctors considered training and educational tasks comprised only a minor part of their work. Furthermore, the educa-
Table 4 Desire for further teaching or training sessions by doctors

\begin{tabular}{ll}
\hline Type of training & Number (\%) \\
\hline MRCP orientated & $26(41)$ \\
Patient management & $15(24)$ \\
Research orientated & $3(4)$ \\
Journal clubs & $2(3)$ \\
Specific topics/state of the art lectures & $2(3)$ \\
'Formal teaching' & $2(3)$ \\
No reply & $14(22)$ \\
\hline
\end{tabular}

tional value of clinical activities is reduced if supervision, teaching and instruction by more senior staff is lacking. ${ }^{18}$ Indeed, the survey uncovered inadequate supervision in many cases, particularly in out-patient departments. A similar finding was reported from hospitals in another regional health authority a few years ago, ${ }^{13}$ and subsequently by the Audit Commission. ${ }^{12}$ In addition, previous surveys found that study leave was not granted to many trainees, ${ }^{9}$ and our results suggest that this is a continuing problem. Requests for study leave have to be scrutinised as regards their educational content, but an appreciable proportion could not take study leave because their routine duties would not be covered or because of lack of funds. Similarly, almost none of the trainees we surveyed were able to attend more than two medical meetings weekly because of ward commitments. Overall, less than two-thirds felt they received adequate training and threequarters desired a greater component of designated teaching sessions. Most doctors wanted teaching orientated to patient management and the MRCP examinations. In a study three years ago by the Royal College of Physicians, $50 \%$ of 456 candidates surveyed on completion of their Part II MRCP (UK) examination were critical of their in-hospital teaching. ${ }^{19}$

While some improvements have been made in recent years (eg, establishment of rotational schemes offering better job security and wider clinical experience, reduction in excessive periods of duty and expansion of consultant numbers), much more has to be done to 
address persisting deficiencies. Calman training programmes will begin to be implemented in medical specialities in 1996. These programmes are much shorter than hitherto, and future trainees will be expected to seek consultant posts earlier than is currently the case. ${ }^{15}$

1 NHS Management Executive. Working for patients: postgraduate and continuing medical and dental education. Department of Health, 1991

2 Department of Health. Funding of hospital, medical and dental training grade posts. Directive EL (92)63. London: Department of Health, 1992.

3 General Medical Council. Recommendations of general clinical training. London: General Medical Council, 1992.

4 NHS Management Executive. The new deal: plan for action. Directive EL (94) 17. London: Department of Health, 1994.

5 Barker A, Scotland AD, Challah S, Gainey B, Bayley I. A comparative study of postgraduate medical education in
North East Thames Region. Postgrad Med $\mathcal{f} 1994 ; 70: 722-$ 7 .

Royal Commission on Medical Education (1965-1968). (Todd Report). London: HMSO, 1968.

7 Report of the committee of inquiry into the regulation of the medical profession (Merrison Report). London: HMSO, 1975.

8 Fourth Report from the Social Services Committee Session 1980 81 Medical Education (Short Report). London: HMSO, 1981.

9 Standing Committee on Postgraduate Medical Education. Improving the experience. Good practice in senior house officer training. London, 1991.
There is a real danger that if radical changes to trainees' work patterns and education are not implemented soon, not only morale but also the standard of training for tomorrow's con sultants will fall.

\section{Appendix}

10 Allen I. Doctors and their careers. Research Report 67 ह. London: Policy Studies Institute, 1988.

11 Parker DF. Demoralised doctors. BMF 1990; 300: 56-7. 2 Audit Commission. The doctors' tale: the work of hospit doctors in England and Wales. London: HMSO, 1995.

13 Dillner L. Senior House Officers: the lost tribe. BMF 199 307: 1549-51.

14 Grainger C, Harries E, Temple J, Griffiths R. Joß satisfaction and health of house officers in the Wesi Midlands. Health Trends 1995; 27: 27-30.

15 Department of Health. Hospital doctors: training for the future

16 London: Department of Health, 1993 . Annual Report. BMA, 1995, pp 9-10.

7 Bewley BR. Reorganising medical education. Br $\mathcal{f}$ Hosp Med 1992; 47: 40-3.

18 McKee $M$, Black N. Does the current use of junior doctors in the UK affect the quality of medical care? Soc Sci Meg 1992; 34: 549-58.

19 Royal College of Physicians (London). MRCP (UK) Part Examinations. The SCM asks questions. Members Newslett is 1995; $1: 3$.

\section{QUESTIONNAIRE FOR JUNIOR STAFF ON MEDICAL TRAINING}

1 Is there a person (eg, consultant) or tutor you feel happy talking to regarding your training career or next job?

2 If Yes: Who is this (eg, your present consultant, past consultant, head of department, college tutor)?

Do you feel you have benefited from this 'service'?

If No: Do you think you would like such a person to discuss training/career matters with?

3 Who do you think this should be (eg, a designated person, or left up to you to decide)?

4 Do you get time to go to hospital medical meetings:

once/week, twice/week, more often (please tick or specify)

5 Are there meetings you want to go to but can't?

If so, why not?

How many would you ideally like to attend?

6 Do you feel you get adequate supervision on the ward/out-patients? (please add an comments)

7 Do you feel you get adequate training in your present job?

If Yes: Would you like more?

If No: What would you like?

8 How much of your time is spent on:

a Routine or 'boring' service work

b 'Interesting' work

c 'Training' - eg, learning new techniques and/or experiences in patient management' discussing problems/patients and difficulties with patient management.

d Formal meetings/talks, etc.

9 What other 'training'/education that you are not receiving in your present job would you like\& (eg, MRCP part I tutorials, part II clinicals, presentation and discussion of patien⿷ management)

10 Have you had any problems obtaining study leave? If so, what problems? 